\title{
Attribution of responsibility for injury and long-term outcome of patients with paralytic spinal cord trauma
}

\author{
K Brown ${ }^{1}$, MH Bell ${ }^{1}$, C Maynard ${ }^{2}$, W Richardson ${ }^{3,4}$ and GS Wagner*,5 \\ ${ }^{1}$ Spine Injury Service, Duke University Medical Center, Durham, North Carolina, USA; ${ }^{2}$ Department of Medicine, \\ University of Washington, Seattle, Washington, USA; ${ }^{3}$ Department of Orthopedics, Duke University Medical Center, \\ Durham, North Carolina, USA; ${ }^{4}$ Department of Neurosurgery, Duke University Medical Center, Durham, North \\ Carolina, USA; ${ }^{5}$ Department of Medicine, Duke University Medical Center, Durham, North Carolina, USA
}

\begin{abstract}
Study Design: Survey.
Objective: To assess the association between patients' perceptions of responsibility for the injury and long term outcomes.

Setting: Duke University Medical Center Spinal Injury Service.

Methods: One hundred and forty patients, who suffered spinal cord injuries between 1985 and 1990, were selected to participate in the study, and $26(19 \%)$, including eight with quadriplegia, completed a telephone interview. The mean age at interview was $39 \pm 12$ years and $12 \%$ were women. The mean time from injury to completion of the study was $8.7 \pm 1.5$ years. Attribution of cause of injury, the Craig Handicap Assessment Reporting Technique, and the SF36 mental health depression/vitality surveyed instruments attribution of responsibility for the injury, functional capacity, mental health depression, and vitality.

Results: The majority (18/26) of patients either totally blamed themselves or others for their injuries. Overall, there was no statistically significant association between attribution of injury and long-term outcomes. Outcomes were similar in patients who either totally blamed themselves or others for their predicament.

Conclusion: In this study, long-term outcomes were not influenced by whether patients perceived themselves as being responsible for their injuries.
\end{abstract}

Keywords: paralysis; spinal cord; blame attribution

\section{Introduction}

Spinal cord injury that results in permanent paralysis can significantly change human behavior. After suffering such a devastating event, individuals try to understand how and why the accident occurred. If the injury was perceived to be caused by forces beyond the individual's control, there may be feelings of anger and helplessness. Conversely, if one perceives that he or she personally caused the injury, there could be different responses. First, anger could be directed inward, resulting in depression, or second, the individual could express appropriate sorrow for harmful actions with resolve to rectify the situation, thereby actively participating in rehabilitation. ${ }^{1}$ It is possible that selfblame could be adaptive and ultimately lead to a better long-term outcome.

Previous studies have examined the relationship between individuals' perceptions of responsibility for spinal cord injury and coping behavior and depression at various times after injury. ${ }^{1-7}$ Bulman and Wortman

*Correspondence: GS Wagner, MD, Cardiovascular Division, Duke University Medical Center, Box 3636, Durham, North Carolina 27710, USA studied the effect of attribution on coping during the acute phase of rehabilitation, and found that those who blamed themselves for the accident were better at coping than persons who blamed others for their predicament. ${ }^{2}$ In another study, patients who were evaluated within 18 months of injury and tended to ruminate excessively about the causes of their accidents had poor coping, whereas there was a positive association between self-blame and selfesteem for those who had been disabled for 2 or more years. ${ }^{3}$ However, with the passage of time, how one attributes responsibility for injury has decreasing influence on psychological well being. ${ }^{4}$ Other investigators have concluded that self-blame, while associated with better outcomes in the early phase of rehabilitation, loses its importance with time. ${ }^{5}$ In a meta-analysis of 23 studies examining attribution and adjustment, nine studies confirmed Bulman and Wortman's finding of a positive association between self-blame and coping. ${ }^{6}$ Of the 12 studies that examined others as a source of blame, in ten there was a significant association between blaming others and poor coping. A more recent study found no 
significant linkages between depression and any of the sources of accountability for the accident or injury during the acute phase of rehabilitation. ${ }^{1}$ However, there was a statistically non-significant relationship between self-blame and depression 18-24 months after a spinal cord injury. The results emphasize the importance of assisting patients in resolving the issue of perceived responsibility for injury and focusing on responsibility for rehabilitation. ${ }^{1}$ Finally, a study of 104 men with spinal cord injury demonstrated that self-attribution of responsibility was associated with lower life satisfaction during rehabilitation, but not at 1 year after injury. ${ }^{7}$

The previously mentioned studies examine aspects of the relationship between subjects' perceptions of the accountability for their spinal cord injuries and various psychological factors such as coping or depression mainly during the acute phase of rehabilitation or in the few years thereafter. The present study attempts to examine the relationship between the attribution of blame and long-term outcome, including general functional capability and mental health and vitality. The attribution of blame for a spinal cord injury is not a static perception, and there are many determinants of long-term outcome. Because of this and the small sample sizes common to studies of spinal cord injury, it is extremely difficult to detect statistically significant relationships between attribution of injury and long-term outcome. Nevertheless, the current study is distinctive in its attempt to do this.

\section{Methods}

\section{Patient population}

From 1985 to 1990,158 patients with spinal cord injury and without prior psychiatric illness or brain damage were admitted to the Duke University Medical Center. During hospitalization, 14 patients died, and four were still minors at the time of study. Each eligible subject was sent an introductory letter that included a telephone number to call, if he or she wished to be excluded from the study. Of the 140 letters mailed, 46 were returned as undeliverable without a forwarding address and one indicated the subject had died. The remaining 93 subjects were contacted by telephone, but 49 did not answer or had disconnected numbers. In addition, the family members of 15 patients were contacted, with the result that seven subjects had died during follow-up and eight were unavailable for interview. Of the remaining 29 subjects personally contacted by the interviewer, three did not wish to participate in the study. Ultimately, $26(19 \%)$ individuals were interviewed. Table 1 displays the baseline characteristics of all 158 patients, as well as the 26 who participated in the study. The major difference between participants and non-participants was that there was a much lower occurrence of quadriplegia in the former group. No data regarding completeness of the paralysis were available.

\section{Study design}

This cross sectional study was designed to examine the association between attribution of injury and functional outcome after an accident that occurred on average $8.7 \pm 1.5$ years prior to injury. A one time only telephone interview, conducted by the first author, was used to assess attribution of injury and functional outcome and also assessed general information, including level of injury, time since injury, age, race, gender, level of education, employment status, socioeconomic status, family support, and financial security. ${ }^{8,9}$ On average, it took $10 \mathrm{~min}$ to complete the survey. The study protocol was approved by the Duke University Medical Center Institutional Review Board.

\section{Attribution measures}

Attribution theory posits that individuals try to find explanations for causes of significant life events. ${ }^{10-12}$ To assess an individual's attribution of accountability for his/her spinal cord injury, the following sources of blame were posited: oneself (to what extent the subject

Table 1 Baseline characteristics

\begin{tabular}{|c|c|c|c|c|}
\hline Variable & $\begin{array}{l}\text { All patients } \\
\quad(\mathrm{n}=158)\end{array}$ & $\begin{array}{l}\text { Study participants } \\
(\mathrm{n}=26)\end{array}$ & $\begin{array}{l}\text { Non participants } \\
\quad(\mathrm{n}=132)\end{array}$ & $\mathrm{P}$ \\
\hline Time since injury (years) & $8.4 \pm 1.6$ & $8.7 \pm 1.5$ & $8.3 \pm 1.6$ & 0.24 \\
\hline Age (years) & $45 \pm 20$ & $39 \pm 12$ & $46 \pm 22$ & 0.12 \\
\hline Quadriplegia & $55 \%$ & $31 \%$ & $61 \%$ & 0.004 \\
\hline Race $(\%)$ & & & & 0.73 \\
\hline Caucasian & $56 \%$ & $62 \%$ & $55 \%$ & \\
\hline Africian-American & $37 \%$ & $35 \%$ & $37 \%$ & \\
\hline Other & $7 \%$ & $4 \%$ & $8 \%$ & \\
\hline Men $(\%)$ & $81 \%$ & $88 \%$ & $80 \%$ & 0.53 \\
\hline Education (years) & NA & $13 \pm 2$ & NA & \\
\hline Employed (\%) & NA & $31 \%$ & NA & \\
\hline Financially secure $(\%)$ & NA & $58 \%$ & NA & \\
\hline
\end{tabular}

NA: Not available 
believed that their injury was caused by themselves or their actions), the environment (meaning to what extent the subject believed that external factors such as the weather caused their injury), chance (meaning to what extent the subject believed that luck or fate caused their injury), or others (to what extent the subject believed that other people caused the injury). ${ }^{5}$ For each of the four sources of blame, the subject was asked to rate the accountability of the accident on a scale from $0-5$, with 0 indicating no accountability and 5 maximal accountability for causing the accident. There was no attempt to reconcile blame attributions among the four sources, and, therefore, a subject may have rated multiple causes with the same level of blame. For example these may be maximal attribution to multiple causes.

\section{Outcome measures}

The survey included the Craig Handicap Assessment Reporting Technique (CHART) questionnaire, as well as both the mental health and vitality sections of the SF36 questionnaire. The CHART technique was designed to assess overall outcome by testing the degree to which people with disabilities are integrated into their communities. It assesses dimensions of physical independence, economic self-sufficiency, occupation, mobility, and social integration. Questions involving activity level, social interaction, financial security and 'free time' were addressed to each subject. ${ }^{13}$

The entire mental health and vitality components of the SF36 questionnaire were used. ${ }^{14}$ The SF36 health questionnaire provides a profile of general health, and because the CHART was designed to assess the functional health of spinal cord injured subjects, these general health questions were not used. The SF36 has been shown to have clinical validity by documenting clear differences between the self-reported health condition of the general population and patients with common illnesses. ${ }^{15}$ The mental health component of the SF36 was designed to measure psychological state and perception regarding feelings of anxiety. It consists of five items, with the lowest score indicating feelings of nervousness and depression all of the time, and the highest score indicating feeling peaceful, happy, and calm all of the time. The vitality component of the SF36 was used to measure overall patient happiness and energy. It consists of four items, with the low score of feeling tired and worn out all of the time, and the high score of feeling full of pep and energy all of the time. The interview was structured so that the questions were initially less personal, then more personal, then again less personal, to attempt to obtain more uniform, less defensive responses.

\section{Statistical methods}

In comparing baseline characteristics of participants and non-participants, the Chi-square statistic was used for categorical variables, and the student's $t$-test was used for continuous variables. Because of the small sample size, non-parametric statistical methods, including the Spearman correlation coefficient, were employed in assessing the association of attribution of blame with outcome in the 26 respondents. The MannWhitney test was used to compare outcomes in 18 patients who totally blamed themselves or others for their injuries.

\section{Results}

Attribution of responsibility

The distribution of attribution of responsibility for the accident is shown in Figure 1. The mean scores for self $(65 \%)$ and chance $(73 \%)$ as sources of blame were very similar, while only $19 \%$ attributed any degree of blame to the environment. Attribution of responsibility to others was intermediate $(46 \%)$ between these extremes. Of those who blamed themselves for the accident, $53 \%$ assumed maximal blame, whereas of those who blamed chance, $42 \%$ attributed the accident solely to chance. Attribution of total blame to self $(35 \%)$ chance $(31 \%)$ and others $(35 \%)$ were remarkable similar. Interestingly 'others' were either blamed totally or not at all (Table 2).

There was a high negative correlation between the score for self and others (Spearman $r=-0.80$, $P<0.0001)$, such that those who placed high blame on themselves attributed little or no responsibility to others. For example, of the nine individuals who maximally blamed themselves for the accident, none attributed responsibility to others. Of the nine individuals who placed maximal blame on others, only one attributed minimal blame to himself or herself. There were no statistically significant associations between the other sources of attribution. Furthermore, there was no association between attribution of sources of blame and baseline characteristics such as age, gender, education, years since or level of injury.

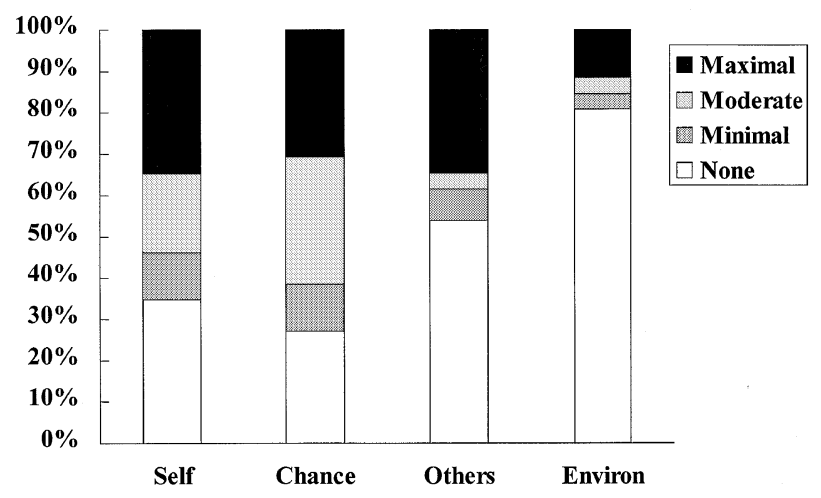

Figure 1 Distribution of attribution scores by source of blame. (The none category is equivalent to score 0 , minimal to 1 or 2 , moderate to 3 or 4 , and maximal to 5 ) 
Association between attribution of blame and outcome The associations among attribution of blame and outcome, as measured by CHART, mental health and vitality scores, is shown in Table 2, as are the mean outcome scores. There were no statistically significant results for the association between CHART score and the source of blame for the injury. Similarly, there were no statistically significant relationships between the sources of blame and outcomes as measured by the mental health and vitality scores. Finally, baseline characteristics such as age, gender, or years since injury were not related to the three measures of outcome. When the analysis was restricted to 18 patients who totally blamed themselves or others for the accident, there was still no association between attribution and long-term outcome (Figure 2).

\section{Discussion}

According to the study hypothesis, individuals who incur spinal cord injury and accept personal responsibility for their injury develop better coping skills and

Table 2 Association between attribution and outcomes

\begin{tabular}{|c|c|c|c|c|}
\hline Attribution & $\begin{array}{l}\text { CHART } \\
\text { score }^{*}\end{array}$ & $\begin{array}{l}\text { Mental } \\
\text { Health } \\
\text { score }^{* *}\end{array}$ & $\begin{array}{l}\text { Vitality } \\
\text { score }^{* *}\end{array}$ & $\begin{array}{l}\text { Mean } \\
\text { score }\end{array}$ \\
\hline Self & & & & $2.5 \pm 2.2$ \\
\hline $\begin{array}{l}\text { Spearmann } r \\
(P)\end{array}$ & $\begin{array}{r}-0.15 \\
(0.46)\end{array}$ & $\begin{array}{c}0.22 \\
(0.29)\end{array}$ & $\begin{array}{l}0.05 \\
(0.81)\end{array}$ & \\
\hline Chance & & & & $2.7 \pm 2.0$ \\
\hline $\begin{array}{l}\text { Spearmann } r \\
(P)\end{array}$ & $\begin{array}{r}-0.14 \\
(0.48\end{array}$ & $\begin{array}{c}-0.18 \\
(0.39)\end{array}$ & $\begin{array}{c}-0.21 \\
(0.30)\end{array}$ & \\
\hline Others & & & & $2.0 \pm 2.3$ \\
\hline $\begin{array}{l}\text { Spearmann } r \\
(P)\end{array}$ & $\begin{array}{l}0.16 \\
(0.43)\end{array}$ & $\begin{array}{r}-0.02 \\
(0.92)\end{array}$ & $\begin{array}{c}-0.03 \\
(0.88)\end{array}$ & \\
\hline Environment & & & & $0.8 \pm 1.7$ \\
\hline Spearmann $r$ & 0.20 & 0.08 & 0.31 & \\
\hline$(P)$ & 0.32 & 0.71 & 0.12 & \\
\hline Mean score & $402 \pm 85$ & $76 \pm 18$ & $60 \pm 18$ & \\
\hline
\end{tabular}

$*$ Maximal score $=500 ; *$ maximal score $=100$

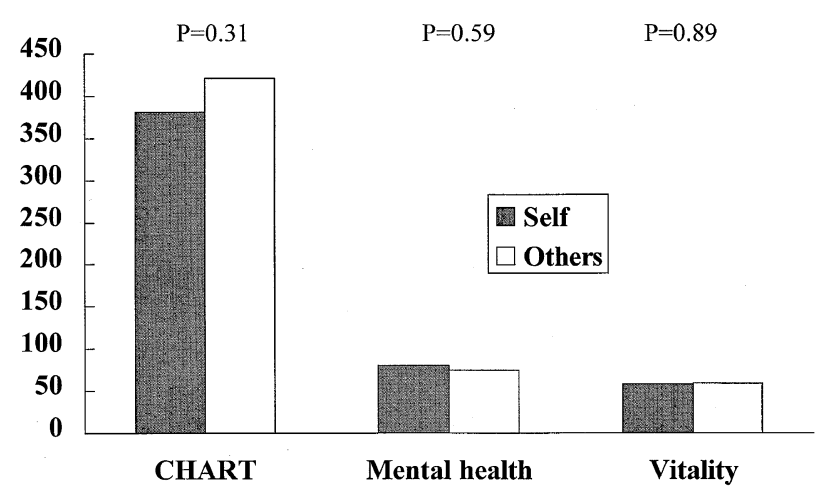

Figure 2 Long-term outcomes in the 18 patients who either totally blamed themselves or others for their injuries less depression in the acute phase of rehabilitation, and as a consequence should have better long-term outcomes. The results, which demonstrated no association between attribution of injury and long-term outcome, do not support this hypothesis. In this study, the majority $(69 \%)$ of individuals either totally blamed themselves or others for their injuries, yet CHART, mental health, and vitality scores were similar in these two distinct groups. While assuming responsibility for the accident in the short-term may be productive, it is apparent that in the long run it has minimal or no influence on outcome. The results are consistent with the observation that the importance of how the injured assign responsibility for spinal cord injury decreases with time. 4,5

\section{Limitations}

A major limitation of the study was that it had limited statistical power to detect statistically significant differences. For example, in order to have an $80 \%$ chance of demonstrating a statistically significant 20 point difference in CHART scores between those who did and did not blame themselves for the accident, 504 individuals would be required. The small numbers of subjects in other similar studies show that spinal cord injured individuals are difficult to enroll in long term follow-up studies. These subjects have special physical and financial needs, and tend to relocate often. The small sample size also precluded the use of multivariate statistical methods that adjust for differences in baseline characteristics such as age, gender, and years since injury.

Another limitation is that over time the individual may change their assessment of blame for the accident. In this study, subjects were asked to assign blame for their injuries almost 9 years after they occurred. For this reason and for others including legal matters, and the fact that the individual may not know who or what is to blame, it may be difficult for the individual to attribute blame to the appropriate source. In addition, the survey itself and the methodology of telephone interview may have been deficient. The questionnaire was structured such that there was minimal interpretation of responses by the interviewer in that the respondent was asked to rate the degree of blame on a scale of $0-5$. While our approach has its limitations, one study has shown telephone interviews to be as effective as in-person interviews. ${ }^{16}$

The CHART and mental health and vitality components of the SF36 were used to assess longterm outcomes. For patients in this study, the mean scores for mental health and vitality components of the SF36 were similar to overall means for the general adult US population. ${ }^{14}$ In the US population, the mean mental health score was $75 \pm 18$ in comparison to $76 \pm 18$ in the current study. For the 26 individuals in this study, the mean vitality score was $60 \pm 18$, and it was $61 \pm 21$ for the US population. The validity and reliability of the SF36 mental health and vitality 
components have been established in numerous studies. There is less experience with the CHART, although it is currently being used as a measure of handicap. ${ }^{17}$

Another deficiency of the study was that measures of attribution and outcome were based on the subjects' own assessments. An alternative measure of attribution is whether one's opinions regarding the cause of the accident approximated the true cause of the occurrence. A patient who accurately perceived reality would be more likely to have an improved functional adjustment and a better overall outcome. If a patient misperceived reality, then such a distortion could result in worse outcome. The subject's view of the cause of injury could be compared with that of an unbiased observer. It could then be determined, after adjusting for other baseline characteristics, how concordance or discordance influenced long-term outcome. A recent study reported that agreement or disagreement between patient and staff attributions was not predictive of outcome.

\section{Conclusion}

The hypothesis that individuals who have spinal cord injury and accept personal responsibility for that injury have improved outcome is not supported by this study. In short, there was no relationship between perceptions of accountability and long-term outcome. Although assuming blame for spinal cord injury may ease the time of transition after injury, in the long term such behavior appears to have little or no influence on outcome.

\section{Acknowledgements}

We thank Thomas Haney and Cara Gambill for their critical review of the study proposal, as well as all of the members of the Spine Team at Duke University Medical Center. This study was supported by the Galen S Wagner Clinical Cardiology Training Fund.

\section{References}

1 Reidy K, Caplan B. Causal factors in spinal cord injury: patients' evolving perceptions and association with depression. Arch Phys Med Rehabil 1994; 75: $837-842$.

2 Bulman RJ, Wortman CB. Attributions of blame and coping in the 'real world' severe accident victims react to their lot. $J$ Pers Soc Psychol 1997; 35: $351-363$.

3 Van Den Bout J, Van Son-Schoones N, Schipper J, Groffen C. Attributional cognitions, coping behavior, and self-esteem in inpatients with severe spinal cord injuries. J Clin Psychol 1988; 44: $17-22$.

4 Schultz R, Decker S. Long-term adjustment to physical disability: the role of social support, perceived control, and self-blame. J Pers Soc Psychol 1985; 48: 1162 - 1172.

5 Heinemann A, Bulka M, Smetak S. Attributions and disability acceptance following traumatic injury: a replication and extension. Rehab Psychol 1988; 33: 195-206.

6 Scholomskas D, Steil J, Plummer J. The spinal cord injured revisited: the relationship between self-blame, other-blame and coping. J App Soc Psychol 1990; 20: 548-574.

7 Richards JS, Elliot TR, Shewchuk RM, Fine PR. Attribution of responsibility for onset of spinal cord injury and psychosocial outcomes in the first year post-injury. Rehabil Psychol 1997; 42: $115-124$

8 Tate DG, Maynard F, Forchheimer M. Predictors of psychologic distress one year after spinal cord injury. Am J Phys Med Rehabil 1993; 72: $272-275$.

9 Lammertse DP, Yarkony GM. Rehabilitation in spinal cord disorders. 4. Outcomes and issues of aging after spinal cord injury. Arch Phys Med Rehabil 1991; 72: S309-S311.

10 Stenmar L, Nordholm LA. Swedish physical therapists' beliefs on what makes therapy work. Phys Ther 1994; 74: 1034-1039.

11 Heider F. Social perception and phenominal causality. Psychol Review 1944; 51: $358-374$.

12 Timko C, Janoff-Bulman R. Attribution, vulnerability and psychological adjustment: the case of breast cancer. Health Psychol 1985; 4: $521-544$.

13 Whiteneck GG et al. Quantifying handicap: a new measure of long-term rehabilitation outcomes. Arch Phys Med Rehabil 1992; 73: $519-526$.

14 Ware Jr J, Kosinski M, Keller S. SF-36 physical and mental health summary scales: a user's manual. 3rd rev. edn. The Health Institute, New England Medical Center: Boston, 1994.

15 Eiser JR. Social psychology: attitudes, cognition, and social behavior. Cambridge England: Cambridge University Press; 1986.

16 Rintala DH, Willems EP. Telephone versus face to face mode for collecting self reports of sequences of behavior. Arch Phys Med Rehabil 1991; 72: $477-481$.

17 Tate D, Forchheimer M, Maynard F, Dijkers M. Predicting depression and psychological distress in persons with spinal cord injury based on indicators of handicap. Am J Phys Med Rehabil 1994; 73: $175-183$. 